\title{
Sex differences in visual-spatial ability: The role of performance factors
}

\author{
DAVID GOLDSTEIN, DIANE HALDANE, and CAROLYN MITCHELL \\ Duke University, Durham, North Carolina
}

\begin{abstract}
Two studies were designed to explore the role of performance factors as sources of the frequently noted higher male scores on visual-spatial ability tests. In the first study, the mental rotations test (MRT) was administered to male and female college students of equally high quantitative ability (based on SAT math scores). Although males had significantly more correct responses on the test than did females, their advantage was eliminated when the ratio of correct responses to items attempted was used as the dependent measure. In the second study, the same test was administered to new groups of male and female college students. In this sample, the males had significantly higher SAT math scores. The MRT was administered under standard, timed conditions and under untimed conditions. Both raw and ratio scores were calculated. With SAT math score as the covariate, analyses of covariance indicated that males demonstrated higher performance in the timed, raw-score condition but not in the untimed or in the ratio-score conditions. The theoretical and social policy implications of these studies are discussed.
\end{abstract}

During the past two decades, a massive body of literature on sex differences in cognitive abilities has been produced (for reviews, see Fausto-Sterling, 1985; Halpern, 1986; Linn \& Petersen, 1986; Maccoby \& Jacklin, 1974). One cognitive ability that has been examined in detail is visual-spatial ability, a domain in which males frequently score higher than females (Bouchard \& McGee, 1977; Harris, 1978; McGee, 1979; Sanders, Soares, \& D'Aquila, 1982). ${ }^{1}$ In particular, male performance was higher than female performance on a task that required subjects to mentally rotate three-dimensional arrays of cubes (Sanders et al., 1982). Indeed, the effect size that was obtained in the Sanders et al. study $(d=.8)$ is comparable to "the mean IQ difference estimated between holders of the Ph.D. degree and typical college freshmen" (Cronbach, 1960, p. 174, as cited in Sanders et al., 1982). This sex difference in mental rotation ability is, to date, the largest cognitive sex difference documented in the literature (Halpern, 1989).

The proposed male advantage in visual-spatial ability is not just a laboratory curiosity, however, but has been linked to greater field independence in males (Hyde, Geiringer, \& Yen, 1975; Sherman, 1967) as well as to higher male quantitative abilities (Fennema \& Sherman, 1977). More broadly, a male advantage in the visual-spatial domain has been considered to be a major factor in male dominance in natural science and mathematically

\footnotetext{
The authors wish to thank Lynn Hasher and Rose T. Zacks for their helpful comments on an earlier draft of this manuscript, and John Jost for his assistance with data analyses. The cooperation of Robert N. Sawyer and the staff of the Duke University Talent Identification Program is gratefully acknowledged. Requests for reprints may be addressed to David Goldstein, Duke University Talent Identification Program, Duke University, Durham, NC 27706.
}

related occupational fields (Elmore \& Vasu, 1980; Halpern, 1986).

Many theories have been developed to attempt to explain the nature and origin of sex differences in visual-spatial skill. At least three of these theories have highlighted the role of biological factors. First, a genetic x-linked model has been proposed (e.g., Harris, 1978). According to this view, spatial ability is a recessive trait that is carried on the $\mathrm{x}$-chromosome. Second, it has been suggested that sex differences in brain lateralization are responsible for spatial ability differences (e.g., see Buffery \& Gray, 1972; Levy, 1976). In this view, the male advantage is due to a greater degree of brain lateralization. Third, it has been suggested that the sex difference in the timing of puberty is responsible for the male advantage in spatial ability. For example, Waber $(1976,1977)$ has shown that early maturers, regardless of sex, had lower scores on tests of spatial ability than did late maturers. Therefore, since puberty occurs, on average, earlier in females than in males, the poorer performance of adolescent females would be expected. Other studies have shown that the poor performance of early maturers persists into adulthood (Ray, Newcombe, Semon, \& Cole, 1984; Sanders \& Soares, 1986).

All of these approaches have met with considerable skepticism. Caplan, MacPherson, and Tobin (1985), for example, have criticized these biological approaches on numerous grounds, including the fact that reported sex differences in spatial ability are inconsistent; these sex differences, when they are found, are often extremely small; the studies in which these differences are reported are often methodologically flawed; and, finally, evidence supporting the validity of the construct "spatial ability" is mixed at best. Instead, it has been proposed that sex differences in spatial ability are the result of culturally 
based differences in socialization patterns and sex-typed activities (e.g., Serbin \& Connor, 1979). On the other hand, equally careful reviews and critiques of this literature lend some credence to the idea that sex differences in spatial ability do exist, especially on mental rotation tasks, and may be, at least in part, biologically based (Geary, 1989; Halpern, 1986, 1989; Kimura, 1987). At present, then, there does not appear to be an empirically justified resolution to this debate.

Virtually ignored in this controversy, however, and of potentially considerable importance to our understanding of the sex-difference question, are the effects of experiential and task factors (or, more generally, performance factors) on the spatial task behavior of the two sexes. Regardless of the role, if any, that biological factors may play, task variables-such as time limits or task difficultyand experiential factors-such as previous task exposure or expectations of task success-undoubtedly influence performance and may contribute to the sex differences reported in the literature. Of particular interest is the observation of Maccoby and Jacklin (1974) that males tend to perform tasks quickly, whereas females work more slowly and carefully. The reason for females' slower performance on some types of tasks could be attributed to several possible factors. In the domain of mathematics, Fennema and Sherman (1977) proposed that since females take fewer math courses than do males, they are less familiar with the subject matter and consequently perform more slowly on math tests. Since the math tests used are invariably timed, the lower scores obtained by females can thus be readily accounted for. It may also take females more time to get adjusted to the questions and determine a method of working through the problems (Mayer, 1985), resulting in a reduced rate of responding and leading to lower scores. In support of this observation, Dreyden, Gallagher, and Brounstein (in press) demonstrated that female performance on the SAT math test could be improved more than the performance of males by administering the test under untimed conditions.

In addition to a slower speed of responding, females may have lower levels of confidence in their ability to perform various tasks. For example, Parsons, Adler, and Kaczala (1982) have shown that among highly able math students, females had less confidence in their mathematical ability than did the males. Consequently, females might be more reluctant to guess if they are uncertain of the correct answer to a problem, leading them to commit more errors of omission than are committed by males. Females would thus be penalized by scoring systems that emphasize the number of items correct rather than the ratio of correct items to items attempted.

Factors such as time limits and confidence-induced test strategies could easily influence performance on tasks of spatial ability, as well as on tasks of mathematical ability. To date, however, there are no studies that have directly assessed the impact of such factors on the spatial task performance of males and females.
The purpose of the two studies reported here, then, was to examine the effect of these two key performance factors-test strategy and time limitations-on the performance of males and females on a test of spatial ability.

\section{STUDY 1}

The purpose of the first study was to determine whether taking into account a more cautious response style of females reduces or even eliminates the male-female difference in performance on a task of spatial ability. If females attempt fewer items per unit time or leave more items unanswered when they are uncertain than is the case for males, then any test that uses number correct as the scoring criterion will favor males. Differences between males and females should be substantially reduced with a scoring system that is tied to the number of items attempted. Thus, the hypothesis of this study was that a sex difference in visual-spatial test performance, if found, would be attenuated when the ratio of items correct to items attempted was used as an alternative scoring criterion.

\section{Method}

Subjects. Seventy college students participated in this study, 60 from an introductory psychology course and 10 from a developmental psychology course. The former group received course credit, the latter only the thanks of the experimenters. The subjects were enrolled in a highly selective, private university, where $85 \%$ of the students are liberal arts majors and $15 \%$ are engineering majors. The sample was evenly divided by sex, and the mean age was 18.6 years $(S D=.83$, range $=18-22)$. The mean (self-reported) SAT math score of these students did not differ by sex and reflects the highly selective nature of the university [for males, $M=690.31$, $S D=60.61$; for females, $M=677.27, S D=57.35 ; t(63)<1]$. SAT scores were not available for 5 students. Although these scores are quite high, it is unlikely that they are exaggerated, because they are consistent with the average SAT math score of the student body as a whole ( $M=682$ for the class of 1991).

Procedure. Testing was conducted in small groups of $1-5$ in a quiet laboratory room. Complications during testing led to the elimination of data from 2 male subjects from the sample. The experimental task was the Shepard/Metzler mental rotations test (MRT) developed by Vandenberg and Kuse (1978). This paper-and-pencil test is based on the experimental stimuli of Shepard and Metzler (1971), and has been used extensively in the experimental literature on spatial ability, yielding consistently higher male performance (Sanders \& Soares, 1986; Sanders et al., 1982). Indeed, larger sex differences have been found with this test than with any other test of spatial ability. For example, Sanders et al. (1982) reported that sex accounted for $16 \%$ of the variance on the MRT but only $2 \%$ of the variance on another test of spatial ability, the card rotations test.

The MRT consists of two parts, each with 10 items. Each item contains a test standard (a 10-block, three-dimensional figure), two correct matching figures, and two incorrect "distractors." The subjects are instructed to identify the two correct alternatives, which are identical in structure to the standard but are rotated in space. Each part of the test has a 3-min time limit.

The MRT was administered under standard conditions, but the data were scored according to two criteria. First, the data were scored in the standard fashion-namely, a raw score was obtained representing the number of correct alternatives chosen (maximum 
Table 1

Mean (and $S D$ ) Raw and Ratio Scores on the Mental Rotations Test in Study 1

\begin{tabular}{lcccccc}
\hline & & \multicolumn{2}{c}{ Raw Score } & & \multicolumn{2}{c}{ Ratio Score } \\
\cline { 3 - 4 } \cline { 6 - 7 } Subjects & $n$ & $M$ & $S D$ & & $M$ & $S D$ \\
\hline Males & 33 & 24.82 & 7.05 & & 88.21 & 11.66 \\
Females & 35 & 18.54 & 6.46 & & 84.37 & 14.11 \\
\hline
\end{tabular}

Note-Ratio scores represent the number of correct alternatives chosen from among the items attempted.

score $=40$ ). Second, a ratio score was obtained, representing the number of correct alternatives chosen from among the items attempted. It was hypothesized that males would have higher scores by the first of the criteria, but not by the second.

\section{Results and Discussion}

The mean MRT scores for females and males for each of the two scoring criteria are presented in Table 1. $T$ tests for independent samples confirmed that under the standard, raw-score criterion, males performed significantly better than females $[t(66)=3.83, p<.0003, d=.85]$. However, in agreement with the hypothesis, under the ratio-score criterion, no male advantage was present $[t(66)$ $=1.22, p>.05]$.

These findings suggest that the source of the female deficit on spatial rotation tasks may be due, at least in part, to performance factors such as speed of response and response style. The female students, despite their very high mathematical aptitude, attempted fewer items during the timed test period than did the male students. The males, consequently, had markedly better performance than did the females under the timed conditions. Of course, this type of testing environment is the norm in most school situations and in standardized testing, and its importance cannot be minimized. Nevertheless, if women work more slowly on visual-spatial tasks because of lower levels of confidence rather than because of lower levels of ability, then the timed testing procedure would underestimate their skills. One could then ask what the impact of untimed testing might be on the performance of females. Would the elimination of the time limit on the MRT reduce or eliminate the male advantage on this test? The second study was designed to answer that question.

\section{STUDY 2}

The purposes of Study 2 were to replicate the basic findings of Study 1 with a new sample and to extend the earlier findings by adding a new variable-timed versus untimed test administration-to the procedure. The use of both a raw score and a ratio score, the method used in Study 1, was retained in this study as well. In addition, one change in the procedure was made to eliminate a potential flaw in Study 1. The high level of performance in Study 1 under the ratio-scoring condition ( $88 \%$ and $84 \%$ correct for males and females, respectively) raises the possibility that the lack of a sex difference was due in part to a ceiling effect; that is, males might have done better than females if the task had been more difficult. Therefore, in Study 2, the scoring criterion was made more rigorous by requiring the subjects to choose not just one but both of the correct choices for each test item in order to receive credit. The hypotheses of this study were that female performance would more closely resemble male performance under the untimed than under the timed conditions, and, as in Study 1, that female performance would more closely resemble that of males under the ratio- than under the rawscore criterion.

\section{Method}

Subjects. The subjects in this study consisted of 46 undergraduate students from the same selective university described in Study 1, although no subjects participated in both studies. The sample was equally divided by sex. Unlike the subjects in Study 1 , however, a sex difference favoring males was found on the SAT math test [for males, $M=702.73, S D=83.11$; for females, $M=657.27$, $S D=77.72 ; t(42)=2.17, p<.05]$. SAT math scores were unavailable for 1 male and 1 female.

Procedure. As in Study 1, the subjects were administered the MRT. The test was administered according to the procedure used in Study 1 (the standard procedure), with one exception: after the 3-min time limit for each half of the test had expired, the subjects were asked to draw a line after the last item attempted. Upon completion of both timed halves, the subjects were instructed to return to the unattempted items and were given unlimited time to complete these items. This procedure produced three dependent measures: (1) the number of items correct within the time limit, (2) the ratio of correct items to items attempted within the time limit, and (3) the total number of items correct with unlimited time (i.e., items correct during the timed portion plus additional items correct during the untimed portion). Since all test items were attempted under the untimed condition, the ratio measure was not used. The first two measures were used in Study 1 as well.

\section{Results and Discussion}

As noted above, the females and males in this study, in contrast to Study 1, differed significantly in mean SAT math score. Because SAT math scores were correlated with performance on the MRT for this sample $(r=.28)$, the data were analyzed by analysis of covariance, with SAT math score as the covariate.

The adjusted means for the three measures of performance on the MRT may be seen in the right-hand column of Table 2. The pattern of results is consistent with the hypotheses of the study. Males had significantly more items correct during the timed interval $[F(1,43)=5.88$, $\left.p<.02, \Omega^{2}=.094\right]$, but did not differ from females in terms of the ratio of correct to attempted items during the timed interval $[F(1,43)=1.22, p>.05]$ and total items correct in the untimed condition $[F(1,43)=0.99$, $p>$.05].

It should be noted that the same general pattern of results was obtained even before the effects of SAT math differences were removed. The unadjusted means and standard deviations for the three measures of performance on the MRT may also be seen in Table 2. Males had significantly more items correct during the timed interval $[t(44)=$ $3.07, p<.01, d=.83$ ], but did not differ from females in terms of the ratio of correct to attempted items during the timed interval $[t(44)=1.85, p>.05]$. However, in contrast to the analysis of covariance, there was a margi- 
Table 2

Mean (and $S D$ ) and Adjusted Mean Raw Scores and Ratio Scores on the Mental Rotations Test (MRT) under Timed and Untimed Conditions in Study 2

\begin{tabular}{|c|c|c|c|}
\hline Subjects & $M$ & $S D$ & $\begin{array}{c}\text { Adjusted } \\
\text { Mean } \\
\end{array}$ \\
\hline \multicolumn{4}{|c|}{ MRT Timed-Raw Score } \\
\hline Males & 10.78 & 3.77 & 10.61 \\
\hline Females & 7.26 & 4.01 & 7.62 \\
\hline \multicolumn{4}{|c|}{ MRT Timed-Ratio Score } \\
\hline Males & 78.27 & 16.61 & 75.41 \\
\hline Females & 68.02 & 20.66 & 72.43 \\
\hline \multicolumn{4}{|c|}{ MRT Untimed-Raw Score } \\
\hline Males & 15.96 & 3.13 & 15.12 \\
\hline Females & 14.04 & 3.34 & 14.58 \\
\hline
\end{tabular}

Note $-n=23$ in both groups. Ratio scores represent the number of correct alternatives chosen from among the items attempted in the timed portion of the test.

nal sex difference in favor of males on the total items correct in the untimed condition $[t(44)=2.01, p<.06]$, presumably due to the contaminating effects of SAT math scores.

The results of Study 2, then, replicate and extend the findings of Study 1. Taken together, these two studies suggest that the male advantage on tests of spatial ability is not found under all conditions. Rather, time limits and the use of raw scores contribute substantially to the male advantage. When time limits are removed or when ratio rather than raw scores are used, the performance of females is no longer significantly lower than that of males. Although these generalizations appear to hold when general mathematical aptitude is not controlled, the findings are most striking if SAT math scores either are equal for males and females (Study 1) or are made equivalent by statistical treatment (Study 2).

\section{GENERAL DISCUSSION}

The two studies reported here support the wellestablished finding that, under standard testing conditions, males have higher scores than females on tests of spatial ability-specifically, the mental rotations test (Vandenberg \& Kuse, 1978). Although there is some evidence to support the notion that cognitive sex differences may be disappearing, at least on the SAT and related tests of verbal and quantitative reasoning (Feingold, 1988; Kolata, 1989), the sex difference in spatial ability is still apparent and is a source of considerable controversy (e.g., Caplan et al., 1985).

The contribution of the two studies reported here, however, lies not in the finding that male performance on the MRT was higher than female performance, since such a finding is hardly novel. Rather, the present studies suggest that the male advantage on spatial tasks is found only under certain conditions-namely, when the test is given with strict time limits and when raw scores are calculated. Under different test conditions-namely, with no time limit or with the use of ratio scores-the sex difference is not found.

It is apparent, then, that sex differences in spatial ability are due at least in part to performance or situational factors. Analogous findings from the literature on age differences in cognitive ability may be instructive. Monge and Hultsch (1971), for example, have shown that the well-established difference between college students and elderly subjects on verbal learning tasks can be eliminated when the elderly subjects are allowed either more time to study the material or more time to respond, or both. A similar analysis may be applied to the apparent sex difference in spatial task ability. Males, who may have had more exposure to spatial tasks and more encouragement in this domain (e.g., Eccles, 1985), work more quickly and perhaps more confidently than females. However, this advantage disappears when the premium on rapid performance is taken away. Like the elderly, females may be more cautious and reluctant to respond in domains where they perceive themselves at a disadvantage. $^{2}$

These studies do not settle the argument about the nature of the sex difference in spatial task performance. Clearly, in our culture at least, "higher" performance is frequently equated with "rapid" performance. Virtually all of the major tests in one's educational careerfrom IQ tests to college admissions tests-place a premium on rapid responding. By this standard, the present studies support the claim that males perform better than females on spatial ability tests. Yet, if females are less confident of their ability and perform at a slower rate because of this lack of confidence, it may be the case that the true ability of females is being masked. Presumably, if the confidence of a group of females could be elevated through experimental or other means, their performance on a timed test would be equivalent to that of males.

It should be emphasized that if sex differences on the MRT can be reduced by varying the testing conditions, most, if not all, other cognitive sex differences may be reduced as well, because the sex difference on the MRT is the largest cognitive sex difference found to date. Indeed, although the present studies were done with a nonrepresentative sample of highly capable young adults, it is at the upper end of the distribution where sex differences in cognitive abilities are thought to be the largest (e.g., see Benbow \& Stanley, 1980; Fausto-Sterling, 1985). Thus, it may be possible to demonstrate that, under some conditions at least, females can perform as well as males on any cognitive task. The mutability of cognitive sex differences has recently been noted by Halpern (1989): "Cognitive abilities are heterogeneous, and whether we find gender differences depends on what, who, and when (in the life span) we test" (p. 1157). We would add "how we test" to this list.

In practical terms, the slower rate of female performance on visual-spatial tasks may be of little consequence. Although data were not collected on how long individual subjects took during the untimed administra- 
tion of the MRT, few subjects took longer than $5 \mathrm{~min}$ and no subject took more than 6 min-that is, 3 min longer than the limit under timed administration. In the real world, if women in mathematical or scientific careers take a few minutes longer than men on an occasional visual-spatial task, they may suffer little or no substantive disadvantage.

Finally, the issue of sex differences in task performance has important social policy implications. The underrepresentation of women in mathematical and scientific careers has consistently been noted (e.g., Eccles, 1985; Steen, 1987). Overcoming this underrepresentation may become a matter of grave national concern as the United States meets increasing competition from abroad. If women and men do in fact have comparable spatial-and by extension, mathematical and other cognitive-abilities, neglecting or underestimating these abilities in over half of our citizens will become increasingly self-defeating.

\section{REFERENCES}

Benbow, C. P., \& Stanley, J. C. (1980). Sex differences in mathematical ability: Fact or artifact? Science, 210, 1262-1264.

Bouchard, T. J., JR., \& McGeE, M. G. (1977). Sex differences in human spatial ability: Not an $\mathrm{x}$-linked recessive gene effect. Social Biology, 24, 332-335.

Buffery, A., \& Gray, J. (1972). Sex differences in the development of spatial and linguistic skills. In C. Ounstead \& D. Taylor (Eds.), Gender differences: Their ontogeny and significance (pp. 123-158). Edinburgh: Churchill Livingstone.

Caplan, P. J., MacPherson, G. M., \& Tobin, P. (1985). Do sex related differences in spatial related abilities exist? American Psychologist, 40, 786-799.

Dreyden, J. I., Gallagher, S. A., \& Brounstein, P. J. (in press). The effects of time and direction changes on the SAT performance of academically talented adolescents. Journal for the Education of the Gifted.

ECCLES, J. S. (1985). Why doesn't Jane run? Sex differences in educational and occupational patterns. In F. D. Horowitz \& M. O'Brien (Eds.), The gifted and talented: Developmental perspectives (pp.251295). Washington, DC: American Psychological Association.

ELmORE, P. B. \& VASU, E. S. (1980). Relationship between selected variables and statistics achievement: Building a theoretical model. Journal of Educational Psychology, 72, 457-467.

FAusto-Steruing, A. (1985). Myths of gender. New York: Basic Books.

FeINGOLD, A. (1988). Cognitive gender differences are disappearing. American Psychologist, 43, 95-103.

Fennema, E., \& Sherman, J. (1977). Sex-related differences in mathematics achievement, spatial visualization, and affective factors. American Educational Research Journal, 4, 51-71.

GEARY, D. C. (1989). A model for representing gender differences in the pattern of cognitive abilities. American Psychologist, 44, $1155-1156$.

HALPERN, D. F. (1986). Sex differences in cognitive abilities. Hillsdale, NJ: Erlbaum.

HALPERN, D. F. (1989). The disappearance of cognitive gender differences: What you see depends on where you look. American Psychologist, 44, 1156-1157.

HARRIs, L. J. (1978). Sex differences in spatial ability: Possible environmental, genetic, and neurological factors. In $M$. Kinsbourne (Ed.), Assymetrical function of the brain (pp. 405-522). New York: Cambridge University Press.

Hyde, J. S., Geiringer, E. R., \& Yen, W. M. (1975). On the empirical relation between spatial ability and sex differences in other aspects of cognitive performance. Multivariate Behavioral Research, 10 , 289-309.

KIMURA, D. (1987). Are men's and women's brains really different? Canadian Psychology, 28, 133-147.

Kolata, G. (1989, July 1). Gender gap in tests seen narrowing. New York Times, p. 1.

LEvy, J. (1976). Cerebral lateralization and spatial ability. Behavior Genetics, 6, 171-188.

Linn, M. C., \& Petersen, A. C. (1986). A meta-analysis of gender differences in spatial ability: Implications for mathematics and science achievement. In J. S. Hyde \& M. C. Linn (Eds.), The psychology of gender (pp. 67-101). Baltimore: Johns Hopkins University Press.

Maccoby, E. E., JackLin, C. N. (1974). Psychology of sex differences. Stanford, CA: Stanford University Press.

MAYER, R. (1985). Mathematical ability. In R. J. Sternberg (Ed.), Human abilities: An information processing approach (pp. 127-150). New York: W. H. Freeman.

McGee, M. G. (1979). Human spatial abilities: Psychometric studies and environmental, genetic, hormonal, and neurological influences. Psychological Bulletin, 86, 889-918.

Monge, R., \& Hultsch, D. (1971). Paired associate learning as a function of adult age and the length of anticipation and inspection intervals. Journal of Gerontology, 26, 157-162.

Parsons, J. E., Adler, T. F, \& Kaczala, C. M. (1982). Socialization of achievement attitudes and beliefs: Parental influences. Child Development, 53, 322-339.

Ray, W. J., Newcombe, N., Semon, J., \& Cole, P. M. (1984). Spatial abilities, sex differences, and EEG functioning. Neuropsychologia, 19, 719-722.

SANDERS, B., \& SoAres, M. P. (1986) Sexual maturation and spatial ability in college students. Developmental Psychology, 22, 199-203.

Sanders, B., Soares, M. P., \& D'Aquila, J. M. (1982). The sex difference on one test of spatial visualization: A nontrivial difference. Child Development, 53, 1106-1109.

Serbin, L. A., \& ConNor, J. M. (1979). Sex typing of children's play preferences and patterns of cognitive performance. Joumal of Genetic Psychology, 134, 315-316.

SHEPARD, R. N., \& METZLER, J. (1971). Mental rotation of three dimensional objects. Science, 171, 701-703.

Sherman, J. A. (1967). Problems of sex differences in space perception and aspects of intellectual functioning. Psychological Review, 74, 290-299.

STEEN, L. A. (1987). Mathematics education: A predictor of scientific competitiveness. Science, 237, 251-252, 302.

VANDENBERG, S., KUSE, A. R. (1978). Mental rotations: A group test of three-dimensional spatial visualization. Perceptual \& Motor Skills, 47, 599-604.

WABER, D. P. (1976). Sex differences in cognition: A function of maturation rate? Science, 192, 572-574.

WABER, D. P. (1977). Sex differences in mental abilities: Hemispheric lateralization and rate of physical growth in adolescence. Developmental Psychology, 13, 29-38.

\section{NOTES}

1. It should be noted, however, that studies that fail to find a sex difference generally do not get into print. See Caplan, MacPherson, and Tobin (1985) and Fausto-Sterling (1985) for cogent discussions of this point.

2. Anecdotally, one of the authors has noted over many years that when a copy of the MRT is shown to undergraduate psychology classes, there is inevitably a groan from the audience and mumbled comments on the order of "Ugh, I can't do that." Those making these remarks are invariably female.

(Manuscript received September 11, 1989; revision accepted for publication January 19, 1990.) 